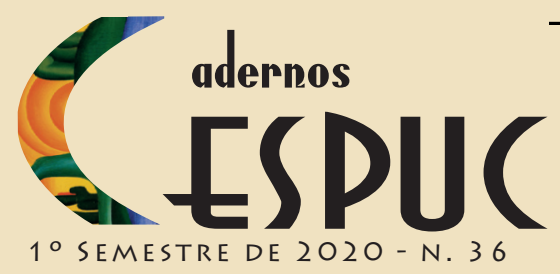

\title{
A POLITICA DO AMOR: (DES)SUBJETIVAÇÃO DOS CORPOS EM LOVE, DE GASPAR NOÉ
}

\author{
Jonatas Aparecido Guimarães*
}

\begin{abstract}
Resumo
Este artigo propõe uma leitura do filme Love, de Gaspar Noé, observando-se os movimentos de (des)subjetivação dos personagens, a partir da perspectiva do controle sobre a vida instaurada pela biopolítica. No decorrer de suas cenas, a produção cinematográfica em análise esvazia um possível subjetivismo que poderia ser sugerido pelo título, de forma que o amor é construído como uma relação puramente corporal. Essa dessubjetivação, mais que um aspecto temático, é incorporada à própria composição estética do filme, cujas fotografias e enquadramentos, ao promoverem a hiperexposição de cenas de sexo, operam uma fusão dos corpos que leva à dissolução dos indivíduos. Procura-se demonstrar, dessa maneira, que há nessa construção estética uma encenação da violência implícita nas relações sexuais e na própria ideia de amor, uma vez que ambos são codificados por discursos que pressupõem, em última análise, o controle da vida e da morte. Por fim, procura-se evidenciar que a produção de Gaspar Noé assume uma dimensão política quando, ao trazer para o palco a hiperexposição da obscenidade, promove uma reconfiguração do sensível que permite entrever possibilidades de reencontro entre o sujeito e o corpo.
\end{abstract}

Palavras-chave: Love. Subjetividade. Corpo. Biopolítica. Obscenidade.

\section{THE POLITICS OF LOVE: (DE)SUBJECTIFICATION OF BODIES IN LOVE, BY GASPAR NOÉ}

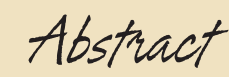

This article proposes a reading of the film Love, by Gaspar Noé, observing the movements of (de)subjectification of the characters, from the perspective of control over life established by biopolitics. In the course of its scenes, the film production under analysis empties a possible subjectivism that could be suggested by the title, so that love is built as a purely bodily relationship. This desubjectification, more than a thematic aspect, is incorporated into the very aesthetic composition of the film, whose photographs and frames, when promoting the hyperexposure of sex scenes, operate a fusion of bodies that leads to the dissolution of individuals. The article wishes to demonstrate, in this way, that there is in this aesthetic construction a staging of violence implicit in sexual relations and in the very idea of love, since both are encoded by speeches that presuppose, ultimately, the control of life and death. Finally, we try to show that Gaspar Noé's production takes on a political dimension in which, by bringing to the stage the hyperexposure of obscenity, promotes a reconfiguration of the sensitive that allows us to glimpse possibilities of reunion between the subject and the body.

Keywords: Love. Subjectivity. Body. Biopolitics. Obscenity.

Recebido em: 21/05/2020.

Aceito em 23/07/2020.

"Professor do Instituto Federal de Educação, Ciência e Tecnologia do Triângulo Mineiro(IFTM). Mestre em Literaturas de Língua Portuguesa Pela PUC Minas. Doutorando em Estudos Literários pela UFMG. https://orcid.org/0000-0002-50127136. 
Sexo não é para gente escrupulosa. Sexo é um intercâmbio de líquidos, de fluidos, de saliva, hálito e cheiros fortes, urina, sêmen, merda, suor, micróbios, bactérias. Ou não é. Se é só ternura e espiritualidade etérea, reduz-se a uma paródia estéril do que poderia ser. Nada. (Pedro Juan Gutierrez)

Entre as diversas produções em que atuou como diretor, Gaspar Noé se notabilizou com o filme Irreversível, lançado em 2002, pela sua feição perturbadora. Fervilharam em uníssono comentários tanto da crítica acadêmica, quanto da jornalística, que apontavam a violência extrema de suas cenas. Nessa produção, o corpo está em evidência de diversas formas, seja no momento em que o casal protagonista descobre que a mulher está grávida, seja na cena de estupro, que dura aproximadamente nove minutos, ou no instante em que um dos personagens, após violenta luta, esmaga a cabeça do outro com um extintor. Essa intensa presença do corpo e da violência também se faz evidente em outros trabalhos de Noé, como o curta-metragem Carne (1991), no qual a mutilação de cavalos se mistura à hiperexposição sexualizada dos personagens, criando um ambiente em que a carne se torna uma massa indistinta, não sendo possível separar claramente a esfera humana da animal.

Se observado comparativamente com essas obras, o filme Love, lançado em 2015, parece, a princípio, fugir do que muitos denominaram como uma estética da violência em suas produções. Isso porque, apesar das constantes cenas de sexo, que colocam o corpo em evidência, não há momentos que envolvam abusos, lutas, mutilações, ou outras formas extremas de agressão física. Isso possibilita o questionamento de qual seria o lugar dessa produção no contexto da obra de Gaspar Noé. Mais que isso, pensando-se em nomes que abordam a relação entre a violência e o corpo como Darren Aronofsky, Takashi Miike, Michael Haneke e Kleber Mendonça Filho no cinema; Pedro Juan Gutierrez, Mario Bellatin e Marcelino Freire na literatura; é possível investigar como o filme Love se insere na produção cultural contemporânea.

Em vista disso, a partir de uma leitura pautada na ótica da biopolítica (Cf. Foucault, 1988), propõe-se observar essa violência não como uma abordagem meramente temática, mas sobretudo como uma construção estética, a partir da qual o corpo/corpus fílmico ganha relevância fundamental. Para tanto, inicialmente este artigo apresentará e problematizará a imagem do erotismo proposta por Bataille (1987) enquanto uma forma de violência contra os seres, com o intuito de abordar o modo como a hiperexposição dos corpos e da sexualidade no filme promove a dessubjetivação dos personagens. Após esse momento, confrontando as ideias de Foucault sobre biopolítica com a imagem do erotismo, discute-se a visão da sexualidade como um domínio sobre o corpo e sobre a vida. Então, procura-se demonstrar o modo como a violência é integrada à própria linguagem fílmica, a partir de uma saturação dos sentidos que compõem as cenas. Por fim, argumenta-se que o filme permite uma discussão política a partir de seu trabalho com a hiperexposição do sexo, a qual vislumbra o possível reencontro entre o sujeito e o corpo.

O título Love, a princípio, poderia sugerir o subjetivismo na abordagem da relação amorosa de um casal. Contudo, o filme de 2015 se destaca das demais produções de Gaspar Noé na medida em que trabalha com o que há de desestabilizador mesmo naquilo que se apresenta como o mais banal. Em vez de um enfoque nos sentimentos, logo de partida essa possível expectativa começa a ser quebrada, com uma cena de sexo explícito em que os corpos masculino e feminino, 


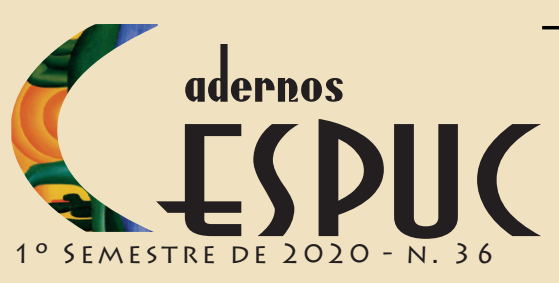

\section{Jomatas Aparecido Guimarães}

ao masturbarem um ao outro, são apresentados em detalhes. Em direção contrária às tradicionais narrativas amorosas que exploram as afinidades sentimentais de um casal, apresentando sua trajetória de vida, nos momentos seguintes apresenta-se uma multiplicação de cenas de sexo, nas quais pouco se revela de uma biografia dos protagonistas Murphy e Electra. De um lado, do rapaz apenas se sabe que é um estudante de cinema que saiu de seu país de origem, os Estados Unidos, para viver na França, sem que quaisquer outros dados sejam revelados. De outro, sabe-se que a moça é uma artista plástica órfã de pai e que tem problemas de convivência com a mãe. No decorrer das cenas, em vez de uma narrativa que permita a individualização dos personagens, ocorre uma progressiva dissolução tanto de seus corpos quanto de suas subjetividades, a partir do momento em que as relações sexuais, que envolviam apenas os dois, passam a envolver outras pessoas. Primeiramente, o casal convida outra mulher, chamada Omi, para ter uma relação a três; essa mesma personagem futuramente engravida de Murphy e provoca a dissolução do relacionamento. $\mathrm{Na}$ sequência narrativa, os namorados visitam uma casa de swing, onde participam de uma cena de sexo grupal. Por fim, pagam a uma transgênero para que possam realizar um ménage à trois. Essas são apenas algumas passagens entre diversas outras cuja construção se desenvolve por meio de um enquadramento e de uma fotografia que leva à confusão dos corpos. Ocorre, assim, uma hiperexposição do sexo, na qual os enquadramentos fílmicos exploram distintos ângulos e posições durante as situações de sexo grupal, de forma que, mesmo que a narrativa se concentre no casal protagonista, suas histórias individuais são solapadas pelo entrelaçamento dos corpos, quebrando o possível subjetivismo do amor implícito no título.

Assim, a hiperexposição sexual conduz à desconstrução da subjetividade, bem como das identidades, borrando as fronteiras do indivíduo, uma vez que os corpos se imiscuem, tornando-se uma massa amorfa de membros, tecidos e fluidos. É esse aspecto que se observa nos enquadramentos seguintes:

\section{Figura 1}

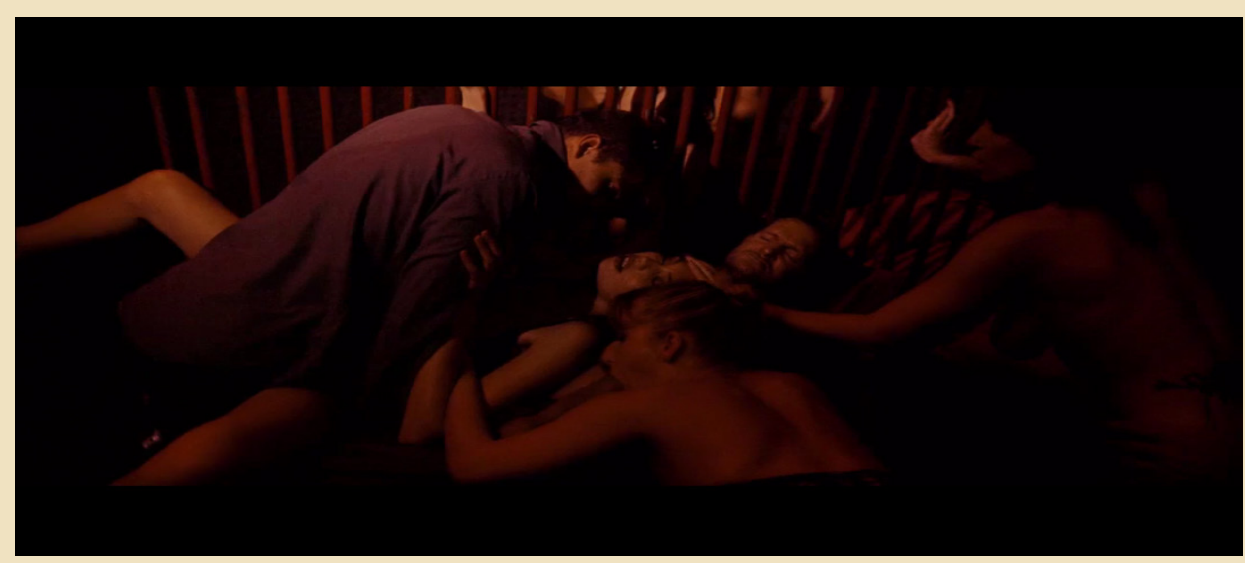

Fonte: NOÉ, 2015, 100:10min. 
Figura 2

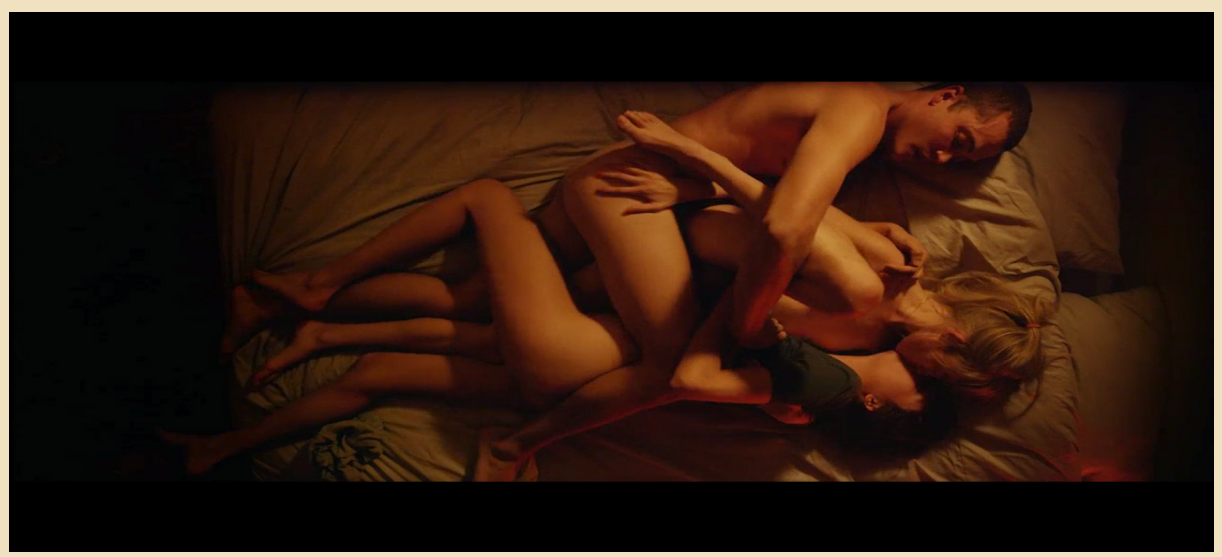

Fonte: NOÉ, 2015, 38:05min.)

Para refletir sobre o movimento dos corpos que se unem no ato sexual, quebrando os limites entre o eu e o outro, cabe trazer à discussão as reflexões de Bataille (1987), quando, ao tratar do tema erotismo, aborda a questão da descontinuidade e/ou continuidade dos corpos. Para ele, uma das características do ser humano seria a descontinuidade, ou seja, a separação ou cisão dos corpos que leva à constituição do indivíduo. Contudo, haveria uma angústia pelo retorno a um estado de continuidade, ou de indistinção dos corpos, de modo que o erotismo operaria justamente essa fusão. Em diálogo evidente com as imagens freudianas de totem e tabu, a obra estabelece os conceitos de interdito, que regularia e limitaria a sexualidade, e de transgressão, que suspenderia o interdito sem suprimi-lo, uma vez que esse só existiria a partir do reconhecimento das regras impostas. Dessa forma, para Bataille, todo o erotismo seria sempre uma forma de transgressão, uma violação. Em outras palavras, o erotismo implicaria uma violência, na medida em que deixariam de existir os corpos separados, para dar lugar a um outro, resultado do amálgama dos anteriores. Com isso, o autor questiona o que significaria o erotismo dos corpos "senão uma violação do ser dos parceiros, uma violação que confina com a morte, que confina com o assassínio?" (BATAILLE, 1987, p. 14). Propõe, então, que "toda a concretização erótica tem por princípio uma destruição da estrutura do ser fechado que é, no estado normal, um parceiro do jogo." (BATAILLE, 1987, p. 14).

Essa passagem tem o mérito de oferecer uma imagem que cria condições para se pensar possíveis relações entre o erotismo e a individualidade. É necessário destacar que o pensamento de Bataille dialoga com a ideia de dissolução do sujeito presente de modo programático em pensadores como Barthes e Blanchot, o que, mais que um diagnóstico, se configura como um direcionamento político do olhar sobre os sujeitos. Ou seja, no contexto da crítica do sujeito francesa que denunciou as estruturas de poder que se impõem sobre o indivíduo, a fusão dos corpos em Bataille tem como pressuposto o objetivo político de se conceber o ser como estruturas abertas para as coletividades. Entretanto, para analisar a construção do erotismo no filme, cabe questionar até que ponto a dissolução das individualidades operada pela suspensão do interdito representaria efetivamente uma alternativa política para as forças que se impõem sobre o indivíduo. Dito de outro modo, a construção fílmica do desmanche das subjetividades se alinharia à visão da libertação do ser, ou colocaria em cena os processos de violência por meio dos quais os sujeitos são assujeitados? 
Nessa direção, é preciso ter cautela para não se pensar que a hiperexposição do sexo, como uma forma de transgressão, significaria, na obra de Gaspar Noé, a simples libertação das amarras por parte dos parceiros. Foucault, em sua obra História da sexualidade (1988), enxerga a sexualidade não como uma força transgressora, que se liberta das interdições sociais, mas como um dispositivo, perpassado por relações de poder que determinam os modos de subjetivação e de existência da sociedade. O filósofo francês não nega a possibilidade de se pensar as relações entre a lei e a subversão previstas pela psicanálise, mas lembra que só podem existir porque ambas fazem parte das relações de poder instituídas, razão pela qual o dispositivo da sexualidade deve ser pensado a partir da perspectiva do contemporâneo:

Essa posição da psicanálise esteve ligada a uma conjuntura histórica precisa. E nada pode impedir que pensar a ordem do sexual de acordo com a instância da lei, da morte, do sangue e da soberania - com todas as referências a Sade e Bataille, com todos os penhores de "subversão" que se lhes peça - seja, afinal de contas, uma "retro-versão" histórica. O dispositivo de sexualidade deve ser pensado a partir das técnicas de poder que lhe são contemporâneas. (FOUCAULT, 1988, p. 140).

Isso implica que no contexto da sociedade burguesa, em vez de, como se pretendia, ser mantido longe dos olhos da sociedade, o sexo se torna cada vez mais visível, assumindo a função de determinar quem somos nós:

Escondido, o sexo? Escamoteado por novos pudores, mantido sob o alqueire pelas mornas exigências da sociedade burguesa? Incandescente, ao contrário. Foi colocado, já há várias centenas de anos, no centro de uma formidável petição de saber. Dupla petição, pois somos forçados a saber a quantas anda o sexo, enquanto que ele é suspeito de saber a quantas andamos nós. A questão sobre o que somos, em alguns séculos, uma certa corrente nos levou a colocá-la em relação ao sexo. (FOUCAULT, 1988, p. 75).

Por essa razão, o sexo e a sexualidade assumem uma dimensão ampla, determinando as identidades e mesmo o controle que o poder exerce sobre o corpo e, consequentemente, sobre a vida. Vale notar que, ainda na obra História da sexualidade, Foucault associa o conceito de biopolítica, com o qual já vinha trabalhando em algumas obras e conferências anteriores, às suas reflexões sobre o sexo, para, a partir dessa abordagem, pensar os modos de controle sobre os corpos e sobre a vida. Nessa esteira, o autor afirma que "deveríamos falar de 'bio-política' para designar o que faz com que a vida e seus mecanismos entrem no domínio dos cálculos explícitos, e faz do poder-saber um agente de transformação da vida humana;" (FOUCAULT, 1988, p. 133).

Adotando-se a ótica biopolítica para analisar o filme Love, é possível afirmar que nele a hiperexposição do sexo não apontaria, referencialmente, para uma libertação do comportamento contemporâneo por meio da transgressão, como poderia sugerir a imagem construída por Bataille. Em lugar disso, o sexo, mesmo em momentos considerados subversivos como a participação em orgias, é sempre um imperativo crivado de regras, é um conjunto de atos e de gestos codificados pelos discursos e pelas instituições. Evidenciar esse jogo de regras que subjazem mesmo ao que se considera como mais transgressor significa colocar em cena a tensão entre o controle 
biopolítico e a (im)possibilidade de se escapar a este. Ou seja, a fusão dos corpos que dilui as individualidades e qualquer possível subjetivismo aponta para as relações de poder existentes na sociedade contemporânea, de modo que os personagens não são sujeitos da própria sexualidade, mas simples corpos. Não se trata simplesmente de atestar a ausência de subjetividade, mas sim da tarefa política de, por meio da própria construção fílmica, operar uma reflexão sobre os modos de subjetivação que instituem o controle sobre a vida.

Seria possível questionar o esvaziamento da subjetividade no filme, argumentando-se que haveria uma história organizada em torno das memórias do protagonista Murphy, pois toda a narrativa seria uma tentativa de rememoração do relacionamento com sua parceira Electra, antes do rompimento do casal. Porém, sobre esse aspecto, as palavras do próprio autor, em entrevista concedida ao site Glamurama, parecem oferecer uma chave de interpretação:

O erotismo desapareceu nos últimos anos, está nos museus e galerias de arte. [...] O casal na minha história faz sexo e amor e isso tudo aparece de uma forma real, eles estão atuando, mas eu queria mostrar também a dor de perder alguém que você ama, quando você está viciado já nessa pessoa. (NOÉ, 2015, s/p).

Nas palavras do diretor, na medida em que o amor é um vício, ele se constrói como algo visceralmente corporal, quebrando a possível identificação de uma subjetividade com a sua memória. Não por acaso, o filme constrói um paralelo entre o uso de drogas e a relação dos protagonistas, uma vez que é a partir do momento em que Electra conhece Murphy que ela começa consumir drogas. Além disso, em um dos momentos em que o rapaz tem uma relação sexual com outra pessoa fora do relacionamento, ele o faz porque a mulher o convida a cheirar cocaína no banheiro de uma boate, onde, por fim, realiza-se o ato sexual. Pode-se mencionar, ainda, que em uma das cenas quando os protagonistas haviam acabado de transar, é desenvolvido o seguinte diálogo: "Electra: Já havia experimentado... fazer sexo chapado de ópio? Murphy: Não... Electra: Relaxante. Murphy: O que você prefere? Electra: Com ópio, com você..." (NOÉ, 2015, 28:08min., tradução livre). É nesse entrecruzamento entre o relacionamento amoroso e o consumo de drogas que Electra presenteia seu parceiro com um punhado de ópio, dizendo que este seria uma espécie de amuleto para protegê-lo se acontecesse algo que a impedisse de estar presente. Após o rompimento do namoro, Murphy usa este presente como um suplemento, sendo que em determinado momento ele consome a droga, como uma forma de fazer sua ex-namorada se tornar um só corpo com o seu novamente, em um movimento expressivamente sexual.

Dessa forma, o filme opera um esvaziamento progressivo da subjetividade do amor, até que os personagens se tornem apenas corpos. Esse processo se revela no pensamento do rapaz, ao se referir a si mesmo: "É, sou só um pau. Um pau não tem cérebro. Um pau só tem um objetivo: foder.” (NOÉ, 2015, 41:53min., tradução livre). Logo, se efetivamente a narrativa se organiza em torno das lembranças dos momentos em que Murphy e Electra ainda eram namorados, essas memórias são construídas de modo corporificado. O ponto de partida para o processo de rememoração é o momento em que o rapaz engole o ópio, como se se unisse sexualmente a Electra. Isso leva à construção de uma memória alucinatória-orgástica, na qual, em vez de um sujeito que se coloca como centro do processo de autorreconstrução, é o corpo quem pulsa na orquestração de reminiscências fragmentárias. 
Mais que uma abordagem temática, o corpo participa da própria construção formal das cenas, a qual se pauta na construção estética da obscenidade tanto no sentido de trazer à tona aspectos do sexo considerados abjetos, como no excesso de elementos que atacam os sentidos. No primeiro sentido, os enquadramentos exploram perspectivas do sexo consideradas socialmente como repugnantes, uma vez que quebram a dimensão do desejo para se aproximar da carne e dos fluidos em uma dimensão estritamente biológica. Em uma das cenas de sexo, a câmera é posicionada frontalmente ao pênis de Murphy, enquanto a parceira o masturba, o que cria a sensação de que este ejacula no rosto do espectador. Em outro instante, após ingerir uma generosa quantidade de ayahuasca, o protagonista começa a vomitar, enquanto têm alucinações advindas do efeito da droga. Nessas alucinações, desenvolve-se uma cena em que uma câmera é posicionada no interior da vagina, possibilitando observar o movimento do pênis que a penetra, bem como a ejaculação que se espalha em seus tecidos, criando um paralelo entre o fluido do vômito e o do esperma. Relembrando a declaração de Noé em sua entrevista, de que o sexo e o amor aparecem "de uma forma real", parece ser possível apontar para a hiper-realidade na construção fílmica, que quebra a perspectiva daquilo que é considerado apresentável sobre o sexo. A esse respeito, é interessante observar a proximidade do que declara Slavoj Žižek (2003), ao comentar o filme O império dos sentidos (1976), comparando-o com a estética da indústria pornô:

E a figura mais extrema da paixão pelo real não seria a opção que nos é oferecida pelos sites pornográficos de observar o interior da vagina do ponto de vista de uma minicâmera instalada na ponta de um pênis artificial que a penetra? Nesse ponto extremo ocorre uma mudança: quando se chega muito próximo do objeto desejado, as fantasias eróticas se transformam em repugnância diante do Real da carne exposta (ŽIŽEK, 2003, p. 22-23).

Tomando como base as palavras de Žižek, se o elemento biológico deveria permanecer subterrâneo aos discursos e a uma estética do que pode ser visto, o filme o desloca desse lugar e o escancara, de forma a colocar em evidência não a subjetividade e os desejos dos amantes, mas sim a crueza dos corpos. Essa crueza se multiplica profusamente durante toda a obra em um excesso cênico a partir do qual os sujeitos são progressivamente esvaziados de seu pretenso domínio sobre o corpo.

Isso posto, cabe aqui estabelecer uma definição mais detalhada para o conceito de obsceno, observando sua aplicabilidade como operador de leitura para o filme. Pelo que se visualizou até o momento, o obsceno é aquilo que deveria ser encoberto como fruto de uma interdição social, mas que em alguns momentos ultrapassa a esfera privada se infiltrando e se propagando pelo espaço público. Pena e Martinelli, discorrendo sobre as ideias de Baudrillard, defendem que contemporaneamente esse conceito poderia ser visto pela ótica da transparência:

Essa associação entre obscenidade e transparência só existe contemporaneamente. No universo moderno, da representação, o obsceno é outra coisa, é o que permanece fora da cena, nas trevas do sistema de representação. Ele é, ainda, o "recalcado", e, enquanto tal, possui uma energia de ruptura, de violência escondida. Já no universo contemporâneo, a obscenidade indica uma sobrerrepresentação: nem escondido, nem recalcado, é a transparência do social, do sexo, da história, do político, como sentido, como evidência. A transparência e a obscenidade levam, portanto, ao êxtase da representação (PENA; MARTINELLI, 2010, p. 1234). 


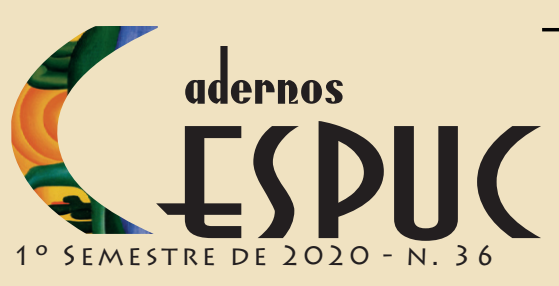

\section{Jomatas Aparecido Guimarães}

Para as autoras, como se vê, haveria duas acepções do termo obsceno: no universo moderno, ele seria aquilo que deveria ser velado, recalcado; no contemporâneo, não seria nem o velado nem o recalcado, mas indicaria uma sobrerrepresentação definida pela transparência. Contudo, na segunda acepção, o termo ainda se liga ao jogo de velar e desvelar instaurado nos domínios de poder estabelecidos. Importa, então, notar que ambas as acepções envolvem o movimento de estar fora/dentro da cena, a qual se constitui de significantes de ordem social, política, histórica. Embora as autoras não citem diretamente, é possível relacionar suas reflexões ao que Baudrillard denomina como a transparência do mal, na medida em que a sobrerrepresentação, o excesso de visibilidade, termina por gerar o seu oposto: o apagamento. Logo, a transparência do mal, nas palavras do filósofo francês envolveria um processo autoimune da sociedade no sentido de eliminar as alteridades: "toda a nossa sociedade busca neutralizar a alteridade, destruir o outro como referência natural [...] Todo o espectro da alteridade negada ressuscita como processo autodestruidor. Isso é também a transparência do mal.” (BAUDRILLARD, 1996, p. 129). Nesse sentido, o excesso da comunicação leva ao fato de que o outro se torna transparente, não podendo ser visto como contraponto da identidade: "Já não há o outro como espelho, como superfície refletora, a consciência de si está ameaçada de irradiação no vácuo. [...] Já não há negação determinada do sujeito, só há uma indeterminação da posição do sujeito e da posição do outro. $\mathrm{Na}$ indeterminação, o sujeito já não é mais nem um nem outro, é só o Mesmo.” (BAUDRILLARD, 1996, p. 129-130).

Nesse sentido, a paixão do real aludida na entrevista de Noé assume uma feição paradoxal, na medida em que se constrói como um êxtase de representação. Trata-se de trazer para as câmeras a representação de uma realidade que, ao mesmo tempo, foge aos pés, porque inacessível, e que foge ao sujeito, porque este se esvazia. A realidade se caracteriza pela sua obscenidade, vista como excesso e como ausência, simultaneamente dentro e fora da cena, que apaga as subjetividades e alteridades. Assim, a própria composição formal das cenas coloca em pauta um excesso de elementos visuais e sonoros, de forma que o êxtase dos corpos no sexo é também o êxtase do corpo fílmico. Nos recortes seguintes é possível observar como esse excesso de sentidos atinge o campo visual:

Figura 3

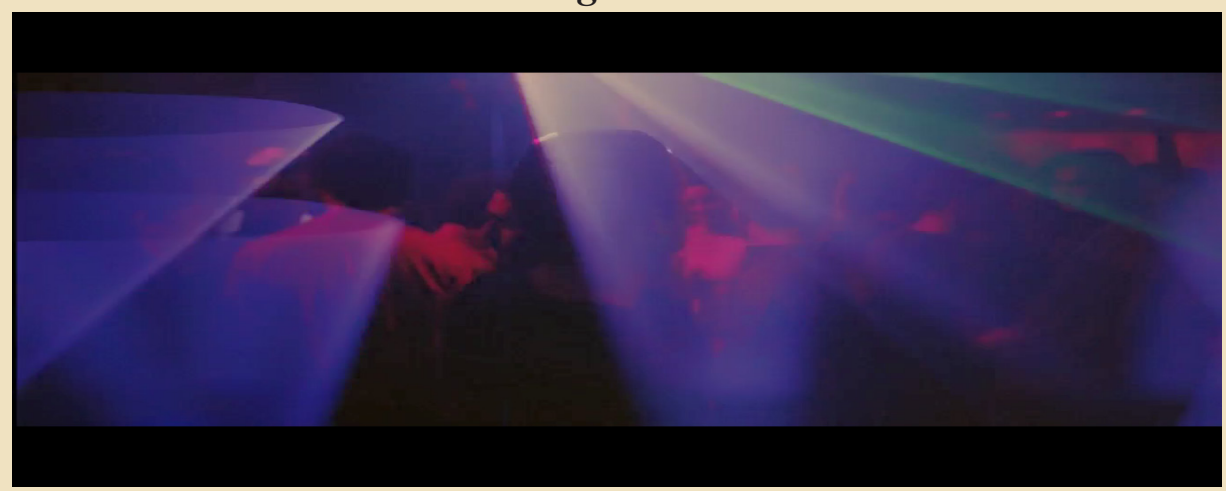

Fonte: NOÉ, 2015, 17:26min. 


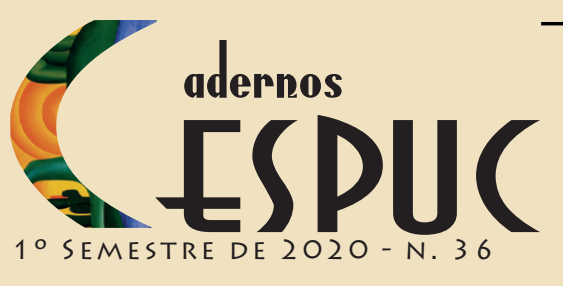

Figura 4

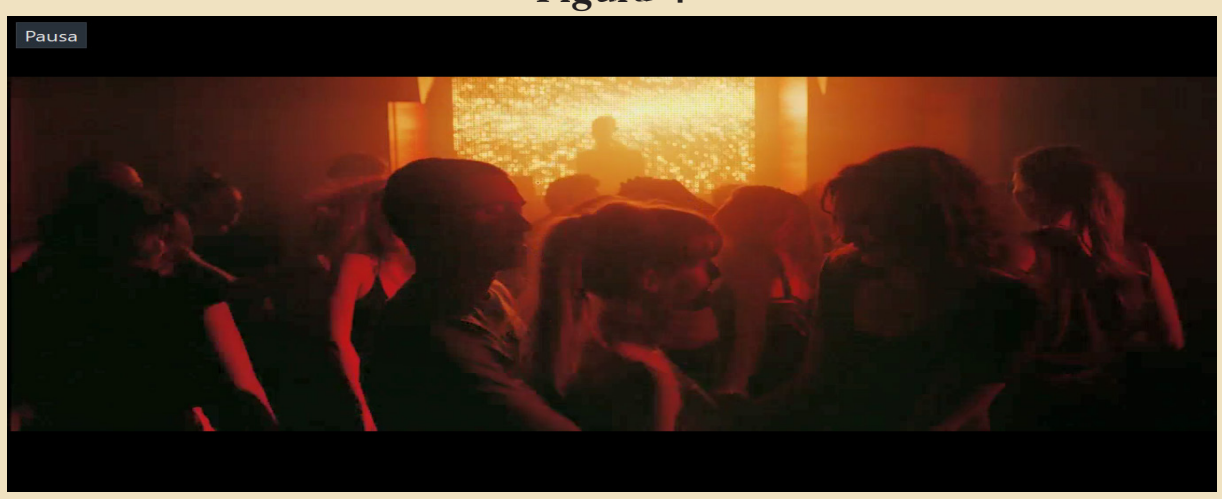

Fonte: NOÉ, 2015, 31:53min.

Figura 5

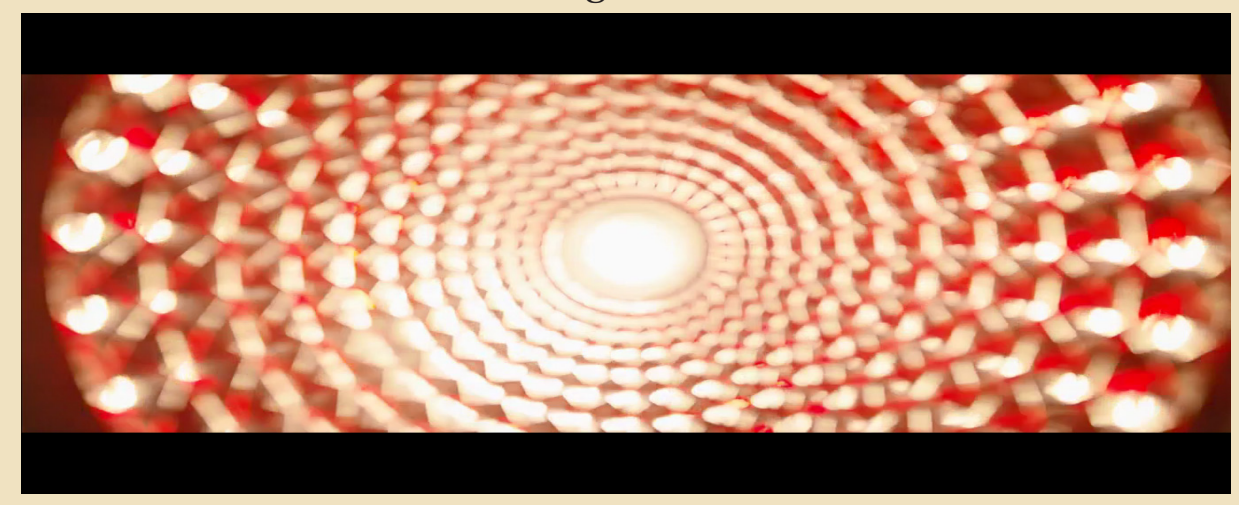

Fonte: NOÉ, 2015, 74:37min.

Figura 6

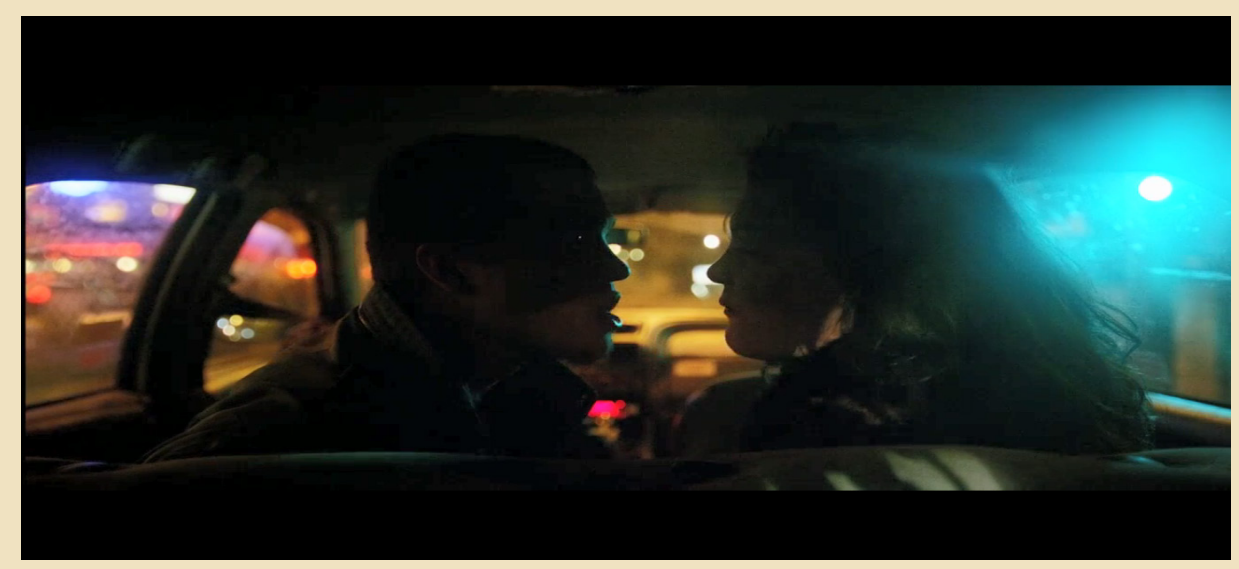

Fonte: NOÉ, 2015, 80:33min. 
A partilha do sensível faz ver quem pode tomar parte no comum em função daquilo que faz, do tempo e do espaço em que essa atividade se exerce. [...] Existe, portanto, na base da política, uma "estética" que não tem nada a ver com a "estetização da política" própria à "era das massas", de que fala Benjamin. Essa estética não deve ser entendida no sentido de uma captura perversa da política por uma vontade de arte, pelo pensamento do povo como obra de arte. Insistindo na analogia, pode-se entendê-la num sentido kantiano -eventualmente revisitado por Foucault $\neg$ - como o sistema das formas a priori determinando o que se dá a sentir. É um recorte dos tempos e dos espaços, do visível e do invisível, da palavra e do ruído que define ao mesmo tempo o lugar e o que está em jogo na política como forma de experiência. A política ocupa-se do que se vê e do que se pode dizer sobre o que é visto, de quem tem competência para ver e qualidade para dizer, das propriedades do espaço e dos possíveis do tempo. (RANCIÈRE, 2009, p. 16-17).

Se, como disse Foucault, a sexualidade como dispositivo ocupa um lugar fundamental para o controle dos corpos e da vida, enquanto discursos incandescentes que determinam quem somos nós, o filme traz ao palco justamente esse excesso de visibilidade. Contudo, desloca esse excesso, evidenciando elementos biológicos habitualmente considerados baixos. Utilizando as palavras de Rancière, a partilha do sensível determina o que pode ser dito e o que não pode ser dito, bem como, por extensão, aquilo que pode se marcar pelo excesso do dizer.

Nesse caminho, a reconfiguração do sensível por meio da hiperexposição do corpo enquanto carne dessubjetivada termina por denunciar a despersonalização e o assujeitamento promovidos pelas relações amorosas. Roberto Esposito, propondo o conceito do dispositivo da pessoa, afirma que este opera uma separação entre o corpo, considerado a parte animal do ser humano, e o sujeito, considerado a parte espiritual. Em outras palavras, o que ele indica é um movimento biopolítico de controle dos corpos que separa a vida dela mesma, tornando-a eliminável. Conforme declara o autor, a política da personalização “[...] se revela como o terrível dispositivo que, ao separar a vida de si mesma, sempre pode levá-la a uma zona de indistinção com o seu oposto." (ESPOSITO, 2011, p. 32, tradução livre). Por essa razão, o autor denuncia que, em muitas práticas políticas a partir do século $\mathrm{XX}$, as quais colocam em pauta um excesso de personalização, ocorre na realidade uma despersonalização, que subjuga os indivíduos, isto é, a subjetividade implica, contraditoriamente, a sujeição de corpos sem rosto tornados objetos. Desse modo, ele comenta o modo como o processo de sujeição do corpo a um sujeito dotado de razão se constitui como um espelhamento das relações em que o corpo político permite a exclusão de alguns por meio de sua pretensa inclusão, relegando determinados tipos de homem à categoria de coisa: "A categoria da pessoa produz ordem porque leva dentro de si a possibilidade de conflito. Ela cria subjetividade política por meio da linha de divisão que, discriminando uma parte do corpo político, coloca a inimizade no espaço da amizade." (ESPOSITO, 2012, p. 13). Com base nesse diagnóstico, o filósofo italiano propõe uma política da despersonalização, a qual poderia superar o mecanismo de sujeição suposta pelo mencionado dispositivo que, em sua base biopolítica, promoveria a tanatopolítica. Com isso, ele propõe uma filosofia que opere um descentramento do sujeito, de modo a desindividualizar o pensamento em nome das inteligências coletivas e, consequentemente, romper a submissão do corpo à parte considerada espiritual:

${ }^{1}[\ldots]$ se revela como el terrible dispositivo que, al separar la vida de sí misma, siempre puede llevarla a una zona de no distinción con su opuesto. 
Se a inerência do pensamento ao espaço individual do sujeito constitui o epicentro do dispositivo teológico-político da pessoa, não deve surpreender que uma filosofia do impessoal comporte um deslocamento do seu "lugar". [...] Se há algo que aproxima autores perseguidos até a excomunhão, o exílio e a morte como Averróis, Bruno, Spinoza, de outros por longo tempo isolados ou mal compreendidos, como Schelling, Nietzsche, Bergson ou Deleuze, é precisamente uma tendência comum à exterioridade do pensamento em confronto com a interioridade da consciência. (ESPOSITO, 2018, p. 17-18).

A análise do filme em pauta parece tornar possível a problematização da discussão proposta por Esposito, observando-se que em sua narrativa o amor, habitualmente visto como sentimento mais pessoal, termina por promover a dessubjetivação dos amantes. Em vez de uma relação que estabeleça parâmetros construídos pelos próprios personagens a partir de sua vivência e de seus sentimentos, o que o filme revela é uma série de imperativos anteriores e exteriores ao namoro que o codificam e o impessoalizam. Em uma cena em que Murphy se encontra na delegacia por ter agredido o amante de Electra após uma crise de ciúmes, o rapaz defende o princípio de fidelidade para justificar suas ações, associando-o com a sua nacionalidade norte-americana. Nessa associação entre o amor e a nacionalidade, não é propriamente uma identidade o que se evidencia, mas o desejo de justificar a posse do outro evocando princípios morais que são exteriores a si. Em outras palavras, o que está em jogo é o desejo de imposição do poder sobre o outro, colocando-o na condição de objeto, mas que, a despeito da vontade do sujeito agente, termina por assujeitar o próprio eu.

Seguindo esse raciocínio, é possível identificar uma aproximação entre a proposta da política do impessoal com a imagem de Bataille, a partir da qual se rompem os limites do indivíduo na relação sexual. Assim, do mesmo modo como as inteligências coletivas anunciadas por Esposito, a fusão dos corpos poderia ser vista como a perspectiva programática de uma dissolução das relações de poder, em que um não se sobrepõe ao outro, mas se confunde com ele. Contudo, importa chamar a atenção para o fato de que essa proposta também pode conduzir ao risco de se promover um apagamento das relações entre a identidade e a alteridade, uma vez que os corpos se tornam um amálgama. Nessa direção, ao promover uma progressiva dessubjetivação dos personagens, o filme coloca em cena também os processos de apagamento de identidades singulares, como a dos homossexuais e dos transgêneros. Promover a diluição dos contornos individuais dos corpos e dos sujeitos não asseguraria a resistência às relações de poder, visto que também é possível assimilar o corpo do outro devorando-o. O momento em que Murphy engole o ópio como uma forma de se tornar novamente um só corpo com a ex-namorada pode ser visto também como um ato de devoração simbólica que, mais que a reunião amorosa com Electra, representa o desejo de submeter aquela que não é mais a sua mulher. A esse respeito, é sintomático o fato de que o casal termina o seu relacionamento em um cemitério, momento em que Electra declara que, se os dois rompessem, ela desapareceria, confirmando o apagamento progressivo de sua imagem no decorrer das cenas. Com isso, encenase uma tanatopolítica simbólica em que o aniquilamento das subjetividades de personagens que não têm histórias, longe de garantir a sua libertação das amarras do poder, os conduz a uma morte em vida. Assim, diferentemente de produções como Irreversível, o filme Love encena a violência pressuposta nas próprias relações amorosas, a qual está cravada no corpo por discursos que são anteriores aos sujeitos. 


\section{CESPUC}

Logo, o excesso de visibilidade levada às últimas consequências pelo filme desvela e desestabiliza as relações de poder instituídas. Se os imperativos éticos usados por Murphy para defender a fidelidade no relacionamento, na realidade, revelam o assujeitamento daquele que os anuncia, um dos únicos momentos entre as memórias do casal em que estes se apresentam como sujeitos de sua própria história é o instante em que o rapaz tirou fotos e filmou a namorada, tratando-a como uma obra de arte. É representativo o fato de que Murphy declara para Electra que seu único sonho é a produção de um filme que havia projetado:

"Murphy: Quero fazer filmes com sangue, esperma e lágrimas. Electra: (Risos, ironicamente) Mas que fofo! Murphy: Essa é a essência da vida? Acho que os filmes devem ser feitos disso, ou devem ao menos conter isso!" (NOÉ, 2015, 53:23min., tradução livre).

Nessa fala, a referência metalinguística destaca o fator biológico que deveria ser constituinte dos filmes, o que se assemelha ao próprio Love, de modo que a persona de Murphy e a de Gaspar Noé se confundem. A esse respeito, é interessante lembrar que sangue e esperma são elementos que constituem a vida. Não sendo por acaso que os dois personagens que compõem o casal são artistas, é no momento em que se pode enunciar a arte que o indivíduo singulariza o seu rosto, quebrando a cisão entre a subjetividade e o corpo. Assim, pode-se vislumbrar um contexto em que o sexo e o amor não se encontram mais presos à determinação de identidades e de subjetividades dóceis, mas promovem o reencontro do sujeito com o corpo, com a vida. O filme não apresenta o corpo apenas como um aspecto temático, mas, uma vez que traz os sentidos para sua composição formal, deve ser lido com o corpo, como corpo/corpus. Então, uma vez que a partilha do sensível se refere aos recortes sensíveis de determinada comunidade, a partir de Love é possível pensar em uma comunidade das subjetividades em comunhão com seus próprios corpos, sem qualquer ideal utópico. Uma comunidade que vive.

\section{Referências}

BATAILlE, Georges. O erotismo. Tradução Antonio Carlos Viana. São Paulo: Lp\&M, 1987.

BAUDRILLARD, Jean. A transparência do mal: ensaio sobre os fenômenos extremos. Tradução Estela dos Santos Abreu. 2 ed. Campinas: Papirus, 1996.

CARNE. Direção: Gaspar Noé. Paris: Les cinemas de la zone, 1991. DVD (40 min.): son, color,; (Imovision, França).

ESPOSITO, Roberto. Dois: A máquina da teologia política e o lugar do pensamento. Tradução Henrique Burigo. Belo Horizonte: Editora UFMG, 2018.

ESPOSITO, Roberto. El dispositivo de la persona. Tradução Heber Cardoso. Madrid: Amarrotu, 2011.

FOUCAULT, Michel. História da sexualidade I: a vontade de saber. Tradução Maria Thereza da Costa Albuquerque e J. A. Guilhon Albuquerque. 13 ed. Rio de Janeiro: Edições Graal, 1988. 


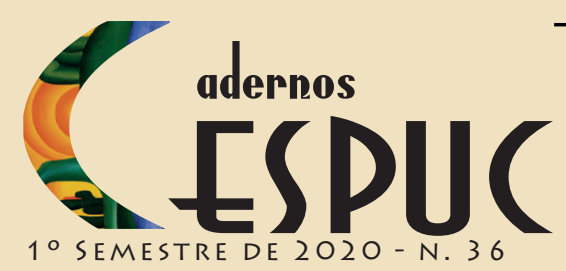

\section{Jomatas Aparegido Guimarães}

IRREVERSÍVEL. Direção: Gaspar Noé. 120 Films, Les Cinémas de la Zone, StudioCanal, 2002. DVD (99 min.): son, color,; (Imovision, França).

LOVE. Direção: Gaspar Noé. Paris: Les cinemas de la zone, 2015. DVD (129 min.): son, color,; (Imovision, França, Estados Unidos).

NOÉ, Gaspar. Love: o erotismo desapareceu. Disponível em: <https://glamurama.uol.com. br/um-papo-com-gaspar-noe-diretor-de-love-o-erotismo-desapareceu/>. Acesso em: 09 dez. 2018.

PENA, Ondina Pereira; MARTINELLI, Verônica. O Real é Morto: Baudrillard e Lacan, dissidentes da comunicação. Revista Mal-estar e Subjetividade, vol. X, núm. 4, dez., 2010, p. 1221-1243, Universidade de Fortaleza: Fortaleza.

RANCIÈRE, Jacques. A partilha do sensível. Tradução Mônica Costa Neto. São Paulo: Editora 34, 2005.

ŽIŽEK, Slavoj. Bem vindo ao deserto do real: cinco ensaios sobre o onze de setembro e datas relacionadas. Tradução Paulo Cezar Castanheira. São Paulo: Boitempo Editorial, 2003. 